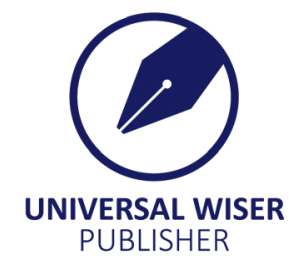

\title{
Modification of Citric Acid Technology Using Electrodialysis
}

\author{
B. Igliński", G. Piechota, P. Iwański
}

Nicolaus Copernicus University in Toruń, Department of Chemistry, Gagarina 7, 87-100 Torun, Poland

Email: iglinski@chem.umk.pl

\begin{abstract}
Modification of conventional citric acid technology has been proposed. Calcium citrate was converted into sodium citrate, which then went through electrodialysis with a bipolar membrane. The electrodialysis was carried out using the following membranes produced by Tokuyama Corporation (Japan): bipolar Neosepta BP, anion-exchange Neosepta ACM, cation-exchange Neosepta CMX; as well as the membranes produced by FumaTech GmbH (Germany): bipolar FBM, anion-exchange FAB and cation-exchange FKB. It was found that there are important relations between current efficiency, current density and energy consumption. The comparison of commercially available membranes shows that the FumaTech GmbH membranes are better - they have a higher efficiency and lower electric power consumption. Moreover, in case of the Tokuyama Corporation membranes, a considerable increase in solution temperature occurred when current density was high. After electrodialysis the acid solution went through crystallisation, which resulted in a product of chemical purity and granulometric composition meeting the criteria of food industry.
\end{abstract}

Keywords: citric acid, electrodialysis, bipolar membrane, crystallization

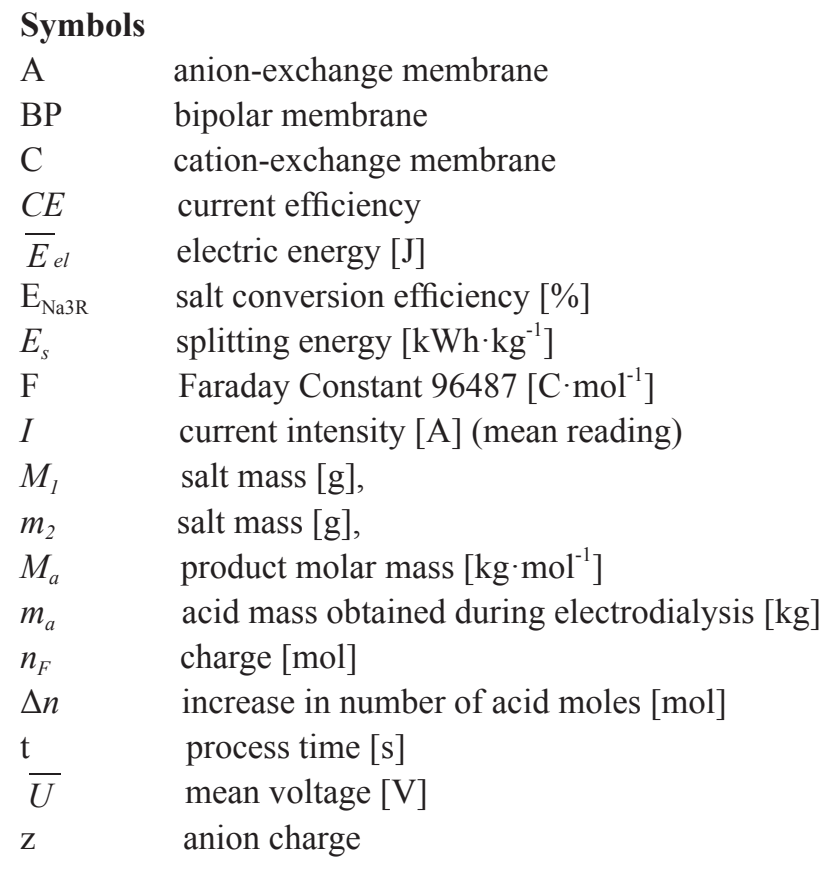

\section{Introduction}

Citric acid (2-hydroxypropane-1,2,3-tricarboxylic acid) is a common natural product from citrus fruit that has been industrially produced since the beginning of the last century ${ }^{[1]}$. Due to its buffering and complex-forming properties as well as its pleasant sour flavour and low toxicity, citric acid is widely used in the production of food, alcoholic and nonalcoholic beverages and in oil manufacture, pharmaceutical, metallurgical, chemical, cosmetics, textile, tobacco, plastics, and plating industries as well as many others ${ }^{[2,3]}$. The world market of citric acid is growing every year. At present, the 
total world production of citric acid and its calcium, sodium, potassium, and magnesium salts amounts to about 1 million tons per year ${ }^{[4]}$.

Citric acid is manufactured commercially by the fermentation of carbohydrates, mainly sucrose or molasses by the selected moulds Aspergillus niger ${ }^{[5]}$. In order to recover acid from the fermentation broth, calcium citrate is precipitated with lime milk; citric acid is precipitated as calcium citrate. It is further treated with sulphuric acid following the removal of waste - gypsum by filtration. This waste, harmful to the natural environment, is produced at the ratio of 3.5 tons of gypsum per 1 ton of anhydrous citric acid ${ }^{[6]}$.

In order to decrease the amount of waste and sewage, the attempts are made to find environmentally-friendly technologies that will not produce harmful waste stored at waste dumps. One of such methods is the electrodialysis with bipolar membrane - an alternative to the conventional method of obtaining citric acid ${ }^{[7]}$. In that process the conversion of tri-sodium citrate to citric acid and sodium base is conducted using energy and ion-exchange membranes ${ }^{[8]}$.

\section{Material and methods}

\subsection{The conversion of calcium citrate to sodium citrate using sodium carbonate}

The investigation of calcium citrate conversion into tri-sodium citrate and calcium carbonate using sodium carbonate (Reaction 1) was carried out in a thermostated reactor of $3 \mathrm{dm}^{3}$ volume, equipped with a mechanical stirrer, a feeder, and a temperature sensor.

$$
\mathrm{Ca}_{3}\left(\mathrm{C}_{6} \mathrm{H}_{5} \mathrm{O}_{7}\right)_{2}+3 \mathrm{Na}_{2} \mathrm{CO}_{3} \rightarrow 2 \mathrm{Na}_{3} \mathrm{C}_{6} \mathrm{H}_{5} \mathrm{O}_{7}+3 \mathrm{CaCO}_{3} \downarrow
$$

Calcium citrate was poured into the reactor whilst sodium carbonate was added drop by drop by the feeder. The process was carried out at the temperature of $20^{\circ} \mathrm{C}, 40^{\circ} \mathrm{C}$ and $60^{\circ} \mathrm{C}$; sodium carbonate concentration was $10 \%$ and the reaction duration was 30, 60, 90 and 120 minutes. The conversion took place at the comparable hydrodynamic conditions; that is, constant stirrer rotations - 50 rotations/minute. After the conversion completion, the citrate solution was decanted and the obtained calcium carbonate sediment was washed in a Büchner funnel. The efficiency of sodium citrate was measured by weighing (after crystallization) whilst purity representing the Ca content was measured by complexometry EDTA and manganometry as well as using thermo-gravimetric analysis (Thermal Analyser Simultaneous TGA-DTA Thermal Analysis made by company TA Instruments). Also, diffractometric analysis was used (X-ray diffractometer X-Pert PRO Systems by Philips).

\subsection{Electrodialysis}

The investigations on sodium citrate conversion to citric acid and sodium hydroxide were carried out using the laboratory electrodialyser TS001 made by FumaTech GmBH, Germany. The electrodialyser consisted of four independent liquid compartments: acid (2), salt (3) and electrode solutions (1,4) (Fig. 1). In the electric field citrate anions migrate through an anion-exchange membrane from compartment 3 to compartment 2. Hydrogen ions, created in a bipolar membrane, are directed to the same compartment, which results in the citric acid production in compartment 2 . The following equation presents the summary reaction:

$$
\mathrm{Na}_{3} \mathrm{C}_{6} \mathrm{H}_{5} \mathrm{O}_{7}+3 \mathrm{H}_{2} \mathrm{O} \rightarrow \mathrm{H}_{3} \mathrm{C}_{6} \mathrm{H}_{5} \mathrm{O}_{7}+3 \mathrm{NaOH}
$$




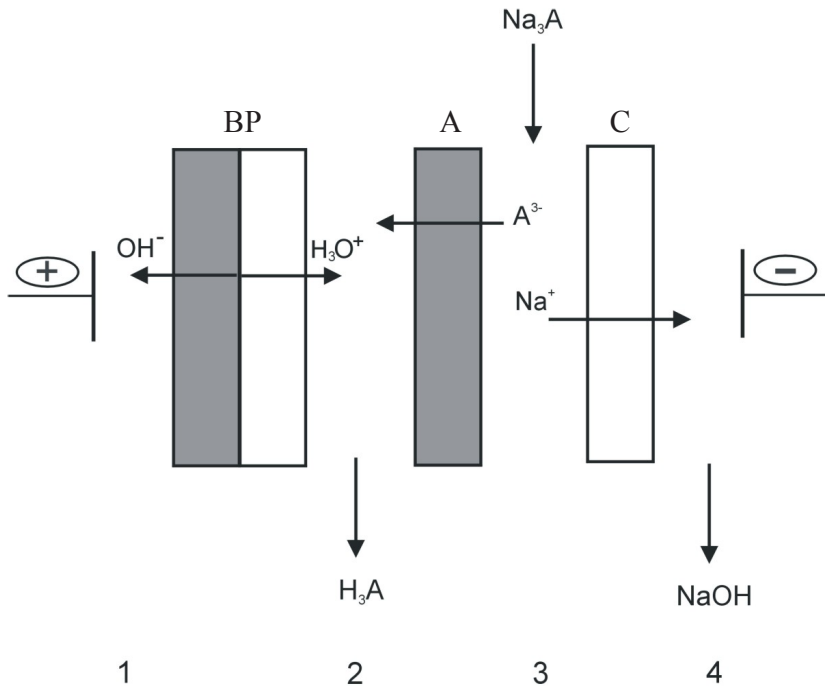

Figure 1. Sodium citrate conversion $\left(\mathrm{Na}_{3} \mathrm{~A}\right)$ to citric acid $\left(\mathrm{H}_{3} \mathrm{~A}\right)$ - the BP-A-C arrangement of membranes;

$1,2,3,4$ - electrodialyser compartments

Each circuit of electrolyte comprised a thermostated tank of solution, a pump, and a flowmeter. The stack was made of polypropylene and was equipped with platinized titanium electrodes. The process was carried out galvanostatically using a constant current power supply (Sorensen 9B2M2, AG Technology, USA).

\subsubsection{Membranes}

The electrodialysis was carried out using the following membranes:

- cation-exchange Neosepta CMX, Tokuyama Corporation, Japan,

- anion-exchange Neosepta ACM, Tokuyama Corporation, Japan,

- bipolar Neosepta BP, Tokuyama Corporation, Japan,

- cation-exchange fumasep® FKB, Fumatech GmbH, Germany,

- anion-exchange fumasep ${ }^{\circledR} \mathrm{FAB}$, Fumatech GmbH, Germany,

- bipolar fumasep® FBM, Fumatech GmbH, Germany.

Table 1. Specifications of ion-exchange membranes

\begin{tabular}{|c|c|c|c|c|}
\hline Properties & $\mathrm{CMX}$ & $\mathrm{ACM}$ & FKB & FAB \\
\hline Thickness $[\mathrm{mm}]$ & $0.14-0.20$ & $0.10-0.13$ & $0.10-0.12$ & $0.09-0.11$ \\
\hline $\begin{array}{l}\text { Ion exchange capacity } \\
{\left[\mathrm{mol}^{-1} \mathrm{~g}^{-1}\right]}\end{array}$ & $1.5-1.8$ & $1.4-1.7$ & 0.8 & 0.8 \\
\hline Electric resistance $\left[\Omega \cdot \mathrm{cm}^{2}\right]$ & $2.0-3.5$ & $3.5-5.5$ & $5-10$ & $2-4$ \\
\hline Selectivity $[\%]$ & 98 & 98 & $>98$ & $>96$ \\
\hline $\begin{array}{c}\text { Mechanical Strength } \\
{\left[\mathrm{kg} \cdot \mathrm{cm}^{-2}\right]}\end{array}$ & 0.40 & 0.15 & no data available & no data available \\
\hline Special features & High Mechanical Strength & Proton Blocking & High Chemical Stability & High Selectivity \\
\hline
\end{tabular}

Table 2. Specifications of bipolar membranes

\begin{tabular}{ccc}
\hline Specification & Neosepta BP & fumasep® FBM \\
\hline Thickness $[\mathrm{mm}]$ & $0.17-0.26$ & $0.20-0.25$ \\
Water Splitting Efficiency [\%] & $>98$ & $>98$ \\
Water Splitting Voltage [V] & $0.9-1.7$ & $>0.8$ \\
Electric resistance $\left[\Omega \cdot \mathrm{cm}^{2}\right]$ & $<3$ & $<3$ \\
Mechanical Strength & $0.4-0.7 \mathrm{MPa}$ & High \\
\hline
\end{tabular}

The effective area per each membrane was $50 \mathrm{~cm}^{2}$. The inter-membrane space was $8 \mathrm{~mm}$ thick. During the electrodialysis process current intensity, voltage, reactants' solutions volume as well as the temperature in the salt and acid compartments were measured every 15 minutes. At the beginning of the process, diluted citric acid solution was introduced to the acid compartment in order to ensure appropriate conductivity.

The molar concentration of electrodialysis products - citric acid and sodium base - was determined potentiometrically, 
using the apparatus Titrino 736 GP made by Metrohm. The measurements were carried out using a combination electrode for $\mathrm{pH}$ measurement. Citric acid was titrated with a standard volumetric solution of sodium base (pH up to 8.1). Sodium

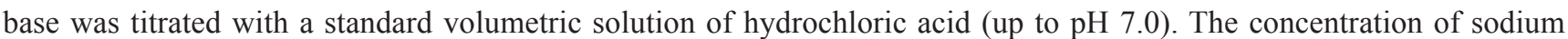
citrate was determined indirectly, by determining the concentration of sodium ions with Flame Atomic Emission Spectroscopy (F-AES).

\subsection{Crystallisation of citric acid}

The condensation of citric acid solution was conducted with a vacuum evaporator LABORATA 4000, made by Heidolph Instruments. The solution of volume of $250 \mathrm{~cm}^{3}$ was condensed at temperature of $90^{\circ} \mathrm{C}$ till saturated solution is obtained; the condensation time was $60-70$ minutes. After that time the thermostat temperature was lowered to $30^{\circ} \mathrm{C}$ and the saturated solution was grafted with citric acid crystals ( $5 \%$ crystalizate).

The crystallisation process along with drying was carried out within 50-80 minutes. The obtained crystals were quantitatively transferred onto filter paper and dried. Due to high hygroscopic properties of citric acid, this product was stored in airtight, opaque containers at temperature lower than $20^{\circ} \mathrm{C}$. The structure of obtained crystals was examined using a scanning electron microscope produced by LEO Electron Microscopy, type LEO 1430VP. A secondary electron capture detector SE and a backscattered electron capture detector BSE were used. The investigation of crystal size distribution was carried out using a stereoscopic microscope STM 712. A population of randomly chosen crystals was sampled and photographic documentation was carried out with a digital camera Pentagram 456. The obtained pictures were then imported to a computer programme CorelDraw 9.0 and the edges of 100 crystals randomly chosen from each sample were measured.

\section{Results and discussion}

\subsection{The conversion of calcium citrate to sodium citrate using sodium carbonate}

The conversion of calcium citrate takes place at the phase boundary between suspension and solution. Consequently, it is advisable to prolong the reaction duration and increase the temperature of reaction mixture. The sodium content was determined by determining the sodium citrate content according to the formula (mass obtained to theoretical):

$$
E_{\mathrm{Na} 3 R}=\frac{m_{1}}{m_{2}} \cdot 100 \%
$$

The efficiency above $90 \%$ was achieved (Figure 2) with the conversion time $t=90$ minutes and temperature $T=40^{\circ} \mathrm{C}$.

It is worth pointing out that potential pollution with calcium ions will not affect the final purity of citric acid as in the system BP-A-C Ca ions are transferred along with $\mathrm{Na}$ ions to the base compartment.

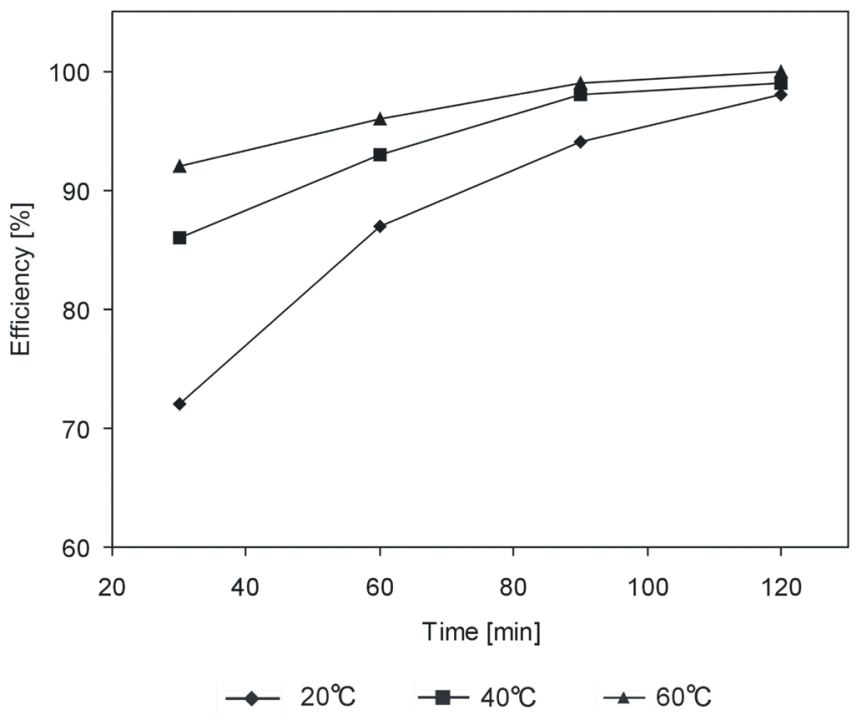

Figure 2. The efficiency of calcium citrate conversion to sodium citrate depending on time for temperatures $20^{\circ} \mathrm{C}, 40^{\circ} \mathrm{C}$ and $60^{\circ} \mathrm{C}$ 


\subsection{Electrodialysis}

During 6-hours electrodialysis it was found that there was a linear increase in acid and base concentration, and at the same time there was a decrease in salt concentration during the time of process. The loss of solvent implied higher salt concentration in the reaction compartment. The change in the volume of electrolyte solution was determined by:

- transport of water molecules due to electro-osmosis and osmosis,

- increase/decrease of substance solved in solution,

- decrease of water due to electrode reactions,

- water splitting in a bipolar membrane,

- solution evaporation, and

- taking samples.

Particular electrodialyses were compared when passed charge was $n_{F}=1 \mathrm{~mol}$.

$$
n_{F}=\frac{I t}{F}
$$

Current efficiency $C E$ was measured using the following formula:

$$
C E=|z| \frac{\Delta n_{k}}{n_{F}}
$$

In formula (5) charge $\mathrm{z}=-3$, because in $\mathrm{Na}_{3} \mathrm{~A}$ solution there are virtually $\mathrm{A}^{3-}$ ions. Within the range of used salt concentrations, basing on the literature data ${ }^{[4]}$ that give dissociation constants $\mathrm{K}_{1}=8.2 \cdot 10^{-4}, \mathrm{~K}_{2}=1.8 \cdot 10^{-5}, \mathrm{~K}_{3}=4 \cdot 10^{-7}, \mathrm{~A}^{3-}$ form was found to be above $99 \%$.

It was also calculated what is the necessary energy amount to produce $1 \mathrm{~kg}$ of monohydrous citric acid as a result of sodium citrate splitting. The electric energy consumption by pumps and a feeder was comparable in a time unit for all electrodialyses, due to which differentiated energy demand:

$$
E_{s}=\frac{\bar{E}_{e l}}{m_{a}}=\frac{\bar{U} I t}{3.6 \cdot 10^{6} \Delta n M_{a}}
$$

The highest current efficiency was found for low current densities (Fig. 3). For the salt concentration $\mathrm{Na}_{3} \mathrm{~A}=0.5$ $\mathrm{mol} \cdot \mathrm{dm}^{-3}$ and $1.0 \mathrm{~mol} \cdot \mathrm{dm}^{-3}$, a decrease in efficiencies is comparable whilst for concentration $\mathrm{Na}_{3} \mathrm{~A}=1.5 \mathrm{~mol} \cdot \mathrm{dm}^{-3}$ this decrease is sharper, especially for Tokuyama membranes. The energy consumption growth follows an increase in current density and is comparable for the values $\mathrm{Na}_{3} \mathrm{~A}=0.5 \mathrm{~mol} \cdot \mathrm{dm}^{-3}$ and $1.0 \mathrm{~mol} \cdot \mathrm{dm}^{-3}$ (Fig. 4). For $\mathrm{Na}_{3} \mathrm{~A}=1.5 \mathrm{~mol} \cdot \mathrm{dm}^{-3}$ a fairly strong increase in energy consumption was found, especially for $j=150 \mathrm{~A} \cdot \mathrm{cm}^{-2}$.

For low current densities current efficiency $C E$ was comparable for Tokuyama and FumaTech membranes $(C E=0.85 \div 0.97)$. Lower $C E$ was found for higher current densities in Tokuyama membranes. The electric current consumption for Tokuyama membranes was higher by about $2 \mathrm{kWh} \cdot \mathrm{kg}^{-1}$ than for FumaTech membranes.
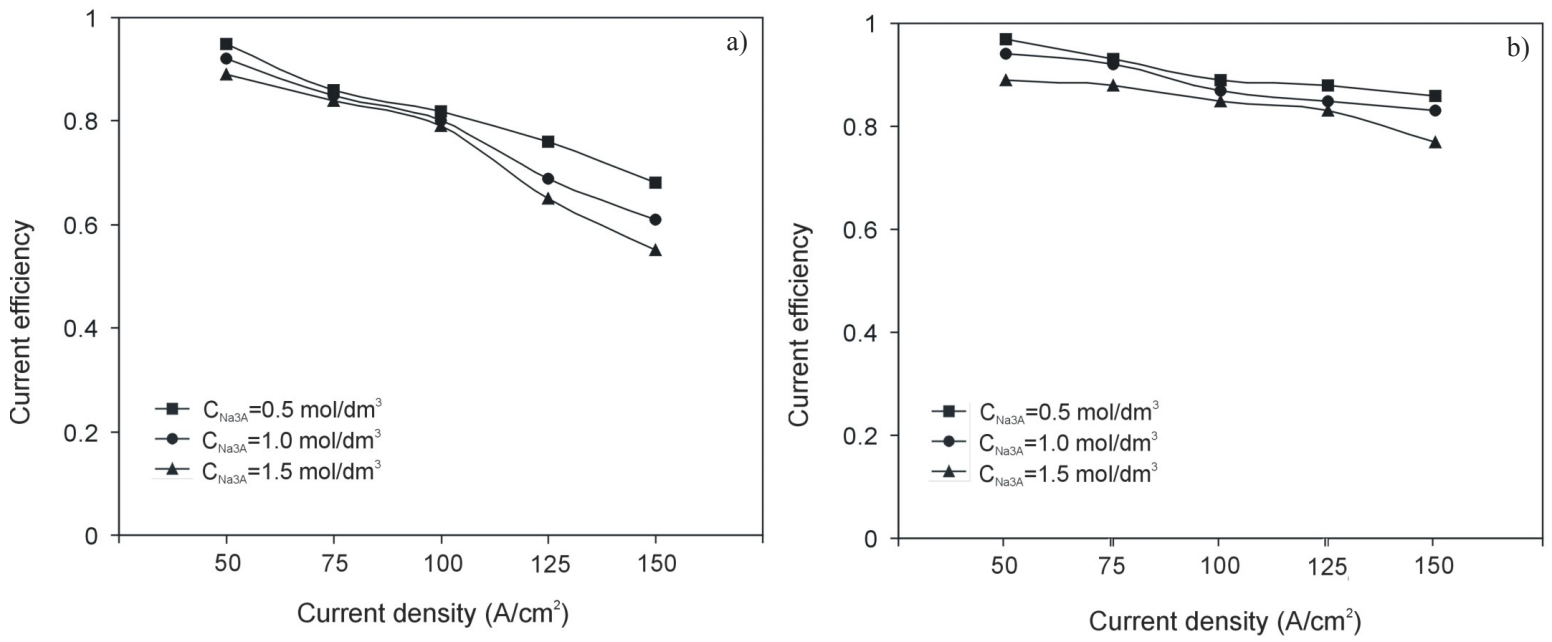

Figure 3. Changes in current efficiency for different salt concentrations: a) - Tokuyama membranes), b) - FumaTech membranes 

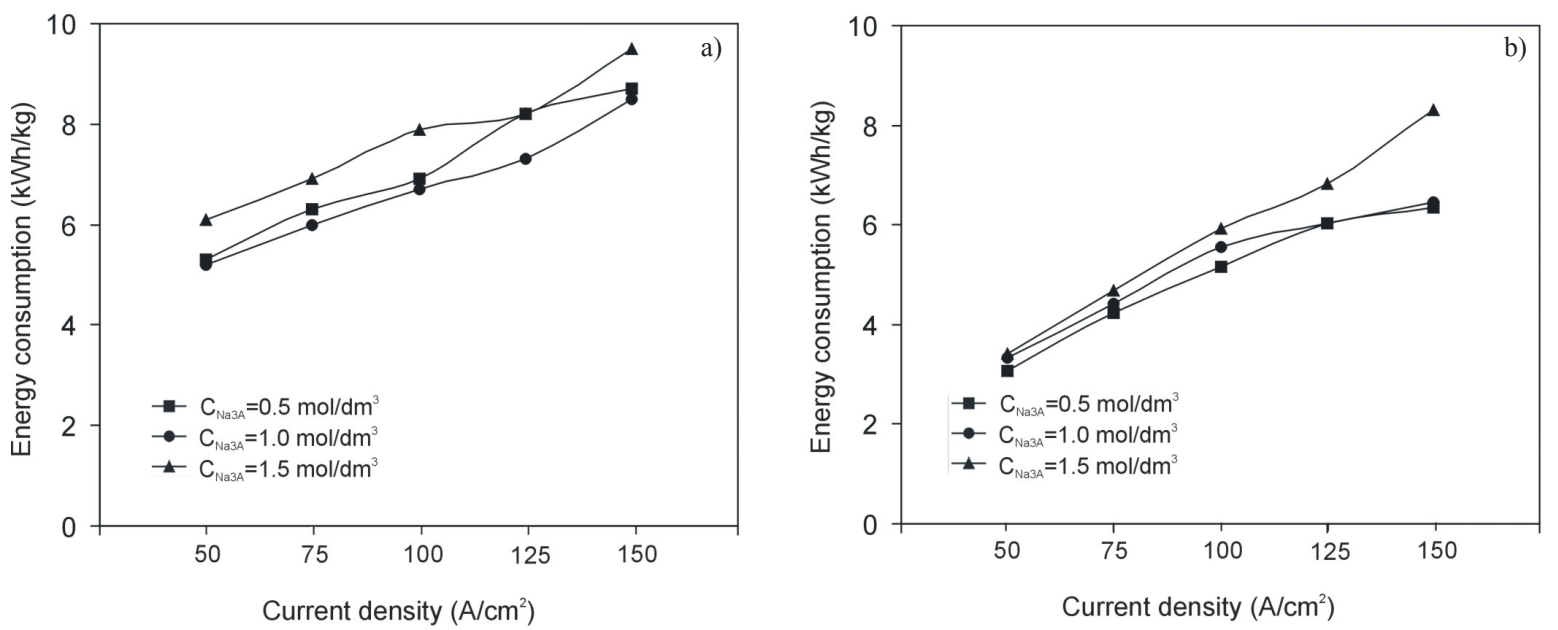

Figure 4. Changes in current efficiency and energy consumption for different salt concentrations (Tokuyama membranes) : a) - Tokuyama membranes), b) - FumaTech membranes

In case of the Tokuyama Corporation membranes, a considerable increase in solution temperature occurred when current density was high. This is due to the high resistance encountered by ions penetrating the membranes of the Tokuyama Corporation.

\subsection{Crystallisation of citric acid}

Fig. 5 shows a geometric form of citric acid crystals. This product crystallises in a monoclinic system. According to the authors, the surface deformations and agglomerates visible in the photos were created in a crystalliser due to crystalcrystal and crystal-reactor interaction. Fig. 6 compares the picture obtained from an SE detector (on the left) and the picture from a BSE detector.
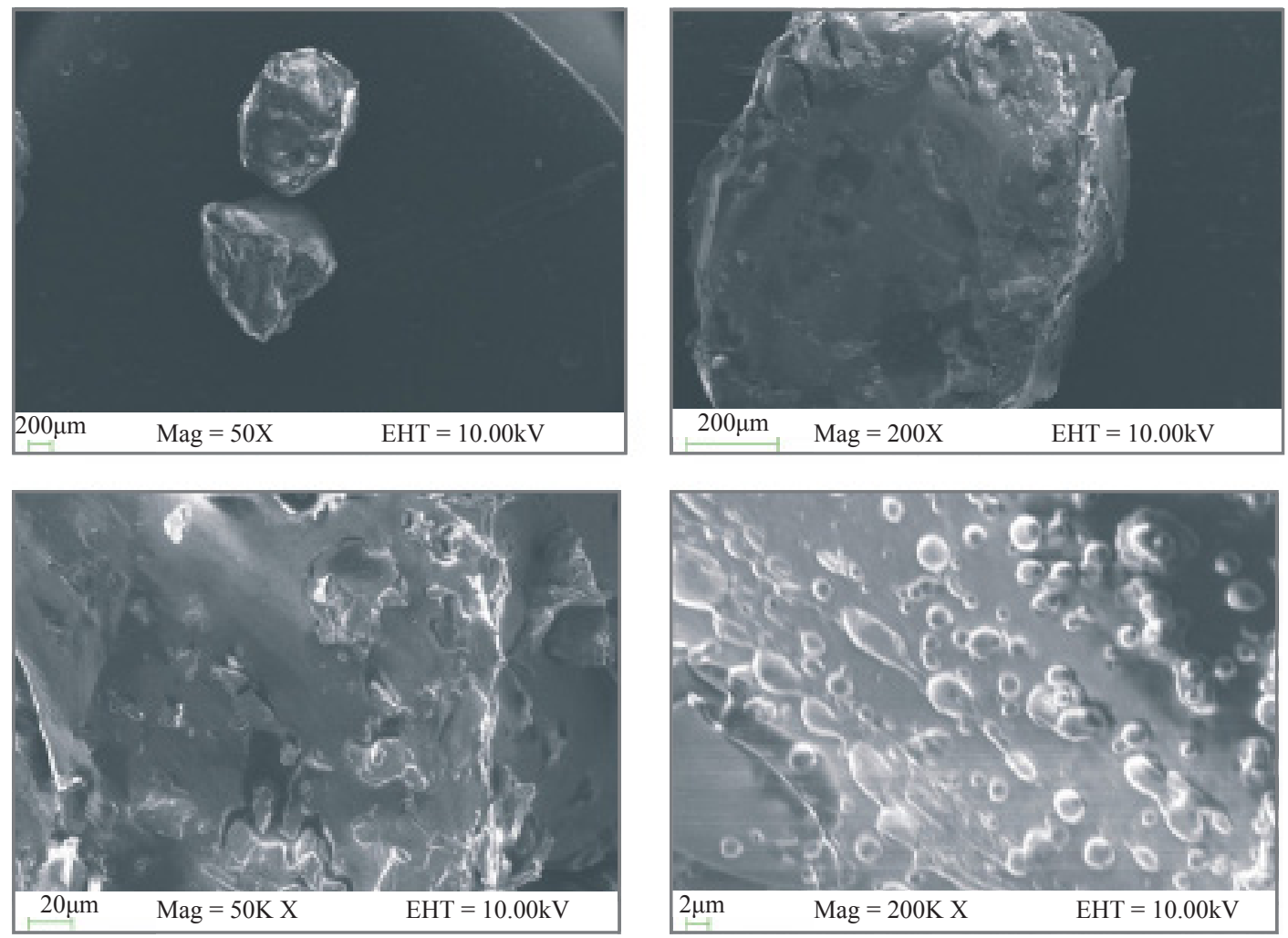

Figure 5. Photos of citric acid crystals, SEM (SE) 


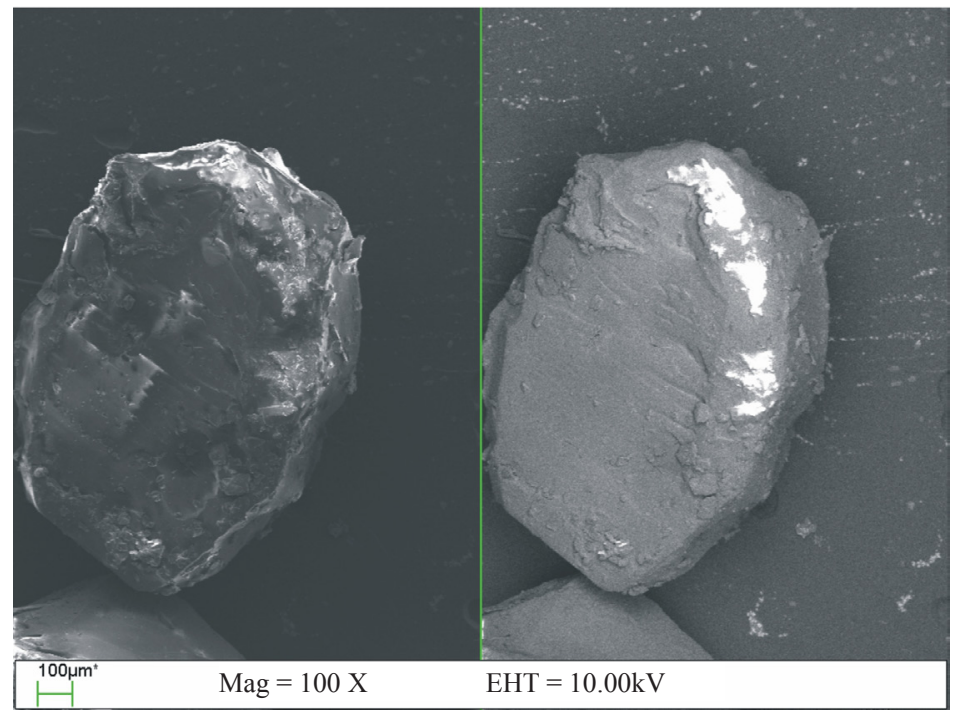

Figure 6. Photos of citric acid crystals, SEM (SE-BSE)

Figure 7 shows the results of crystal size distributions (CSD) after measuring 100 of randomly chosen citric acid crystals. In order to simplify the carried out measurements it was assumed that the crystals of monohydrous citric acid take the form of rectangular prism.

The bigger dimension (length) was marked as $L$, the smaller one (width) as $a$. An advantage of this type of measurement is more efficient computer analysis of the photos.

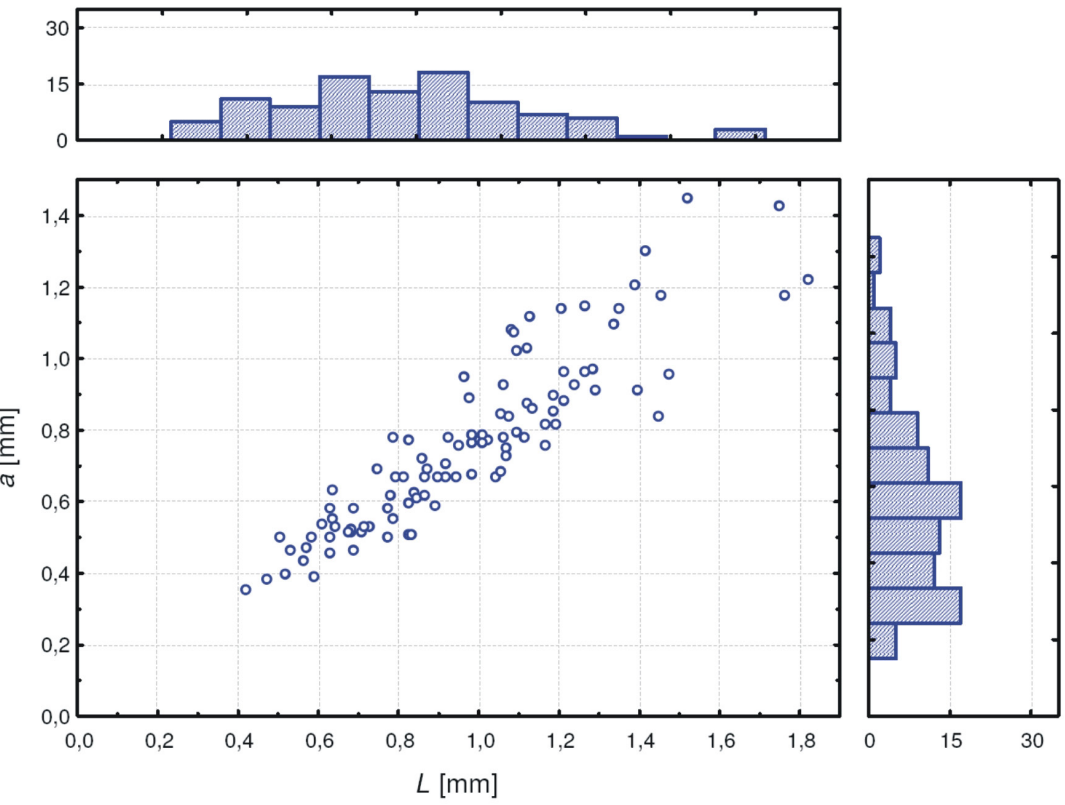

Figure 7. Distribution chart with length (L) and width (a) histograms of citric acid crystals

Obtained citric acid is characterised by a wide spectrum of crystal distribution and minimal mass participation of small crystals fraction, which is of particular advantage in terms of product filtration properties. The carried out tests of citric acid crystallisation led to a product of good granulometric features, resulting in a small mass decrease during filtration and rinsing. The citric acid crystals obtained from sodium citrate electrodialysis are of food industry parameters.

The authors of this publication think that minimal participation of "small" citric acid crystals fraction can be due to the skilful "grafting" of highly oversaturated acid solution during condensation. This result is a practical tip for designing a commercial crystalliser, in which secondary nucleation should be given maximum priority in the zone of high solution oversaturation values. 


\section{Discussion}

It was suggested that a substrate should be obtained in the electrodialysis process - sodium citrate should be obtained as a result of conversion of edible calcium citrate with sodium carbonate. The high efficiency of conversion and the purity of sodium citrate were confirmed.

In literature there are many publications focusing on citric acid production by means of electrodialysis. The comparison is made difficult by the authors using $\mathrm{Na}_{2} \mathrm{SO}_{4}$ as an electrolyte introduced to electrodialyser compartments in order to ensure adequate conductivity as well as various membrane systems.

Tongwen ${ }^{[9,10]}$ was concluded that acid concentration increase in time is linear (he used membranes produced in Chemical Engineering Institute, Shandong). A similar increase was observed in the presented publication. In case of system BP-K-BP Tongwen obtained the highest increase for $C_{\mathrm{Na} 3 \mathrm{~A}}=0.5-1.0 \mathrm{~mol} \cdot \mathrm{dm}^{-3}$ and $C_{\mathrm{Na2SO}}=0.5-1.0 \mathrm{~mol} \cdot \mathrm{dm}^{-3}$, the lowest increase was obtained for $C_{\mathrm{Na3A}}=0.1 \mathrm{~mol} \cdot \mathrm{dm}^{-3}$ and $C_{\mathrm{Na} a S O 4}=0.5 \mathrm{~mol} \cdot \mathrm{dm}^{-3}$. In the presented publication the highest concentration increase was found for $C_{\mathrm{Na} A \mathrm{~A}}=0.7-1.1 \mathrm{~mol} \cdot \mathrm{dm}^{-3}$. Tongwen investigated the changes in current efficiency in time depending on the used membrane system. He concluded that for the systems A-K-BP-A-K and K-BP-K there is a sharp decrease whilst for BP-K-BP efficiency virtually does not change. Additionally, Tongwen noted a positive correlation between splitting energy consumption and increase in $j$. It is worth noting that the values of $E_{s}$ presented by Tongwen are similar to those presented in this publication. The author also compared energy consumption for various membrane systems. The lowest energy consumption was found for the system K-BP-K whilst the highest for BP-A-K-BP.

Pinacci and Radaeli ${ }^{[11]}$ and also Novalic et al. ${ }^{[12,13]}$ used Tokuyama membranes. Pinacci ${ }^{[11]}$ obtained satisfactory current efficiency for a cation-exchange membrane and a bipolar membrane (he does not specify the system). Pinacci concluded that a degree of salt conversion should not exceed $80 \%$ since the electric energy consumption considerably increases afterwards. This is confirmed by the finding of the authors of this paper - a sharp fall in salt concentration with an increase in acid and base concentration implies a great rise in the system temperature. Novalic used the system A-BP-A-K. He concluded that a growth in current density is followed by an increase in energy consumption, which is also confirmed by the presented results.

An increase in $E_{s}$ with an increase in current density was also found by Turek ${ }^{[14,15]}$. He noticed that despite an increase in $E_{s}$ with an increase in current density, the total cost of salt splitting is lower due to the lower investment cost, membrane and module cost. Turning from a laboratory to a commercial level, it is worth noting not only efficiency, but also energy consumption and electrodialysis duration.

Sun et al. ${ }^{[16]}$ chose two bipolar membranes and one cation exchange membrane to stack to form a two-compartment stack configuration. The biggest acid efficiency of $97.1 \%$ was achieved with $3.3 \%$ initial sodium citrate under a current density of $40 \mathrm{~mA} \cdot \mathrm{cm}^{-1}$.

In this article the comparison of the two commercial membrane systems was much more favourable towards the membranes produced by FumaTech $\mathrm{GmbH}$ - higher efficiency $C E$ and lower energy consumption $\overline{E_{s}}$. Initial salt concentration $C_{\text {Na3A }}$ influenced efficiency, the optimum was between $0.5 \div 1.0 \mathrm{~mol} \cdot \mathrm{dm}^{-3}$ and decreased with an increase in $j$. Using too high electrolyte volumes in relation to the membrane surface unnecessarily prolongs the process duration.

The process of electrodialysis is relatively simple; it does not require $\mathrm{pH}$ control and does not impact negatively on the workers' health. In the described membrane system the potential contamination with metal ions will be eliminated from the final product since they will migrate with sodium ions to the compartment where sodium base is generated, which results from the system properties.

The mass crystallisation of citric acid is a stable process. The microscope analysis confirmed that well developed crystals were obtained. No small crystals or agglomerates lowering the product quality were found. Crystals from different samplings vary slightly, which proves that in given conditions mass crystallisation process is fully controlled. Carried out tests of citric acid mass crystallisation in moderate hydro-dynamic conditions and with a precisely defined dose of "grafting" reinforce the purpose of this action to obtain a product of good graining and filtering properties.

The diagram of citric acid technology modification is shown in Fig. 8. The novelty of this method lies in using the conversion of calcium citrate with sodium carbonate to produce sodium citrate as well as electrodialysis with a bipolar membrane, during which high purity citric acid is obtained. Calcium carbonate after washing off impurities is widely used in industry. Similarly, the sodium base can be used in industry. It can also be carbonised to give sodium carbonate needed for calcium citrate conversion. 


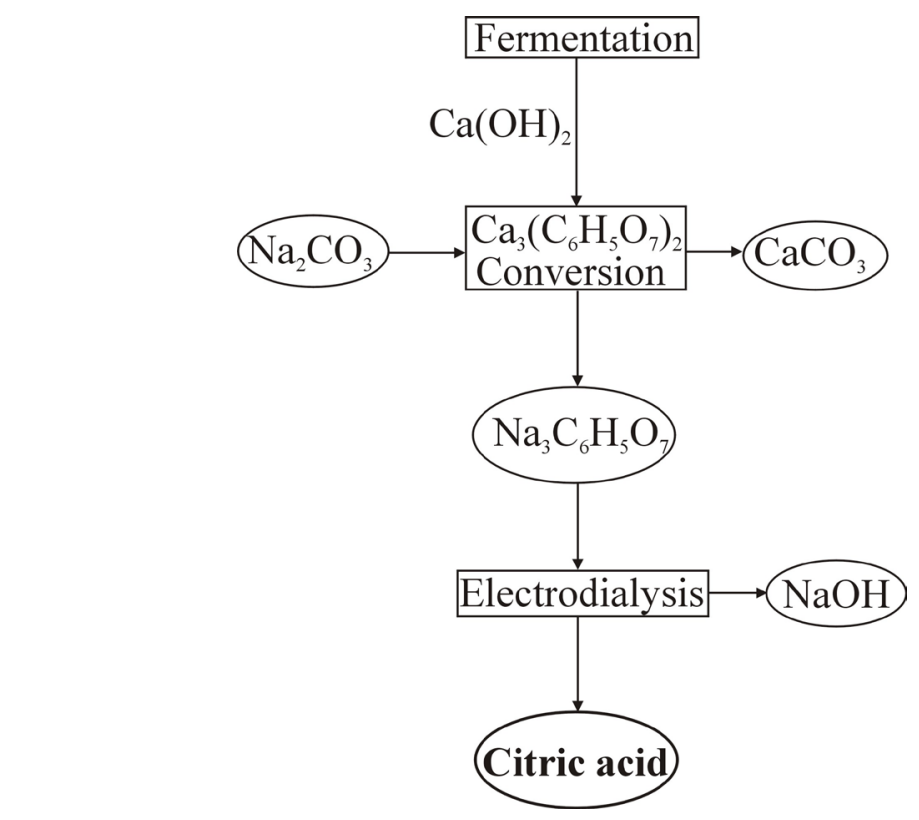

Figure 8. The suggested diagram of citric acid production in the electrodialysis process with bipolar membranes

The citric acid production method presented in this paper corresponds to integrated systems, which are based on the concept of Pure Production. Its goal is to eliminate emission flux, in this case highly contaminated gypsum.

\section{Acknowledgments}

This work was financially supported by the Polish State Committee for Scientific Research (project No 3T09B12128).

\section{References}

[1] Grewal HS, Kalra KL. Fungal production of citric acid. Biotechnology Advances. 1995; 2(13): 209-234. Available from: https://doi.org/10.1016/0734-9750(95)00002-8.

[2] Müller B, Kläger W, Kubitzki G. Metal chelates of citric acid as corrosion inhibitors for zinc pigment. Corrosion Science. 1997; 8(39): 1481-1485. Available from: https://doi.org/10.1016/S0010-938X(97)00061-9.

[3] Müller B. Citric acid as corrosion inhibitor for aluminum pigment. Corrosion Science. 2004; 46: 159-167. Available from: https://doi.org/10.1016/S0010-938X(03)00191-4.

[4] Igliński B, Buczkowski R. Modyfikacje konwencjonalnej technologii wytwarzania kwasu cytrynowego. Przemyst Chemiczny. 2009; 2(88): 148-152. Available from: bwmeta1.element.baztech-article-AGHM-0034-0040.

[5] Currie JN. The citric acid fermentation of Aspergillus niger. Journal of Biological Chemistry. 1917; 1(31): 15-37. Available from: bioRxiv 2019 0: 259051v1-.

[6] Abou-Zeid AZA, Ashy MA. Production of citric acid: A review. Agricultural Wastes. 1984; 1(9): 51-76. Available from: https://doi.org/10.1016/0141-4607(84)90075-1.

[7] Novalic S, Jagschits F, Okwor J, et al. Behaviour of citric acid during electrodialysis. Journal of Membrane Science. 1995; 108: 201-205. Available from: https://doi.org/10.1016/0376-7388(95)00159-X.

[8] Tongwen X, Weihua Y. Citric acid production by electrodialysis with bipolar membranes. Chemical Engineering and Processing. 2002; 41: 519-524. Available from: https://doi.org/10.1016/S0255-2701(01)00175-1.

[9] Tongwen X. Electrodialysis process with bipolar membranes (EDBM) in environmental protection - a review. Resources Conservation and Recycling. 2002; 37: 1-22. Available from: https://doi.org/10.1016/S09213449(02)00032-0.

[10] Tongwen X, Weihua Y. Effect of cell configurations on the performance of citric acid production by bipolar membrane electrodialysis. Journal of Membrane Science. Available from: 2002; 203: 145-153. https://doi.org/10.1016/S03767388(01)00795-5.

[11] Pinacci P, Radaelli M. Recovery of citric acid from fermentation broths by electrodialysis by bipolar membranes. Desalination. 2002; 148: 177-179. Available from: https://doi.org/10.1016/S0011-9164(02)00674-4. 
[12] Novalic S, Okwor J, Kulbe KD. The characteristic of citric acid separation using electrodialysis with bipolar membranes. Desalination. 1996; 105: 277-282. Available from: https://doi.org/10.1016/0011-9164(96)00083-5.

[13] Novalic S, Kongbangkerd T, Kulbe KD. Recovery of organic acids with high molecular weight using a combined electrodialytic process. Journal of Membrane Sciences. 2000; 166: 99-104. Available from: https://doi.org/10.1016/ S0376-7388(99)00247-1.

[14] Turek M. Cost effective electrodialytic seawater desalination. Desalination. 2003; 153: 371-376. Available from: https://doi.org/10.1016/S0011-9164(02)01130-X.

[15] Turek M. Dual-purpose desalination-salt production electrodialysis. Desalination. 2003; (1-3)153: 377-381. Available from: https://doi.org/10.1016/S0011-9164(02)01131-1.

[16] Sun X, Lu H, Wang J. Recovery of citric acid from fermented liquid by bipolar membrane electrodialysis. Journal of Cleaner Production. 2017; 143: 250-256. Available from: https://doi.org/10.1016/j.jclepro.2016.12.118.T. 